\title{
Intrapulmonary Solitary Fibrous Tumour of the Lung: A Very Unusual Presentation
}

\author{
Pınar Yaran1, Abdullah İrfan Taştepe ${ }^{2}$, Ülkü Yazıcı², Serpil Dizbay Sak ${ }^{3}$ \\ ${ }^{1}$ Clinic of Thoracic Surgery, Private Akay Hospital, Ankara, Turkey \\ ${ }^{2}$ Department of Thoracic Surgery, Atatürk Training and Research Hospital for Chest Disease and Chest Surgery, Ankara, Turkey \\ ${ }^{3}$ Department of Pathology, Faculty of Medicine, Ankara University, Ankara, Turkey
}

\begin{abstract}
Solitary fibrous tumour (SFT) is a rare neoplasm which most frequently occurs in the pleura, especially visceral pleura, but it is known that intrapulmonary SFT is very rare. We report the case of a 60-year-old woman who was admitted with a 6-year history of slow enhancing intrapulmonary nodular lesion in her right upper lobe on chest computed tomography (CT). A right upper lobectomy was performed for complete excision of the tumour and the postoperative histopathological examination revealed SFT. No pathology was observed during the period of 34-month postoperative follow-up. Herein we present an extremely rare case of intrapulmonary SFT that was located in the deep pulmonary parenchyma.
\end{abstract}

Key Words: Solitary fibrous tumour, intrapulmonary, localized fibrous tumour

\section{Introduction}

Solitary fibrous tumour (SFT) is a rare neoplasm which most frequently occurs in the pleura, especially visceral pleura $(1,2)$, but it is known that intrapulmonary SFT is extremely rare (3). After several decades of controversies, now it is generally agreed that it originates from mesenchymal cells of submesothelial tissue of the pleura (4). Most of these tumours project into the pleural cavity in a pedinculated manner from the visceral pleura $(2,4,5)$. Inward tumour growth into the lung parenchyma from the visceral pleura is infrequent and a pure intrapulmonary solitary fibrous tumour without morphologic and histologic attachment to the visceral pleura has been described very rarely.

We report here an extremely rare case of an intrapulmonary solitary fibrous tumour located in the deep pulmonary parenchyma completely surrounded by lung tissue.

\section{Case}

A 60-year-old woman was admitted to hospital for investigation of an intrapulmonary nodular lesion in her right upper lobe on chest computed tomography (CT). The nodule was incidentally found on a routine chest roentgenogram taken at another hospital in June 2001. Before then she had been completely free of symptoms. She and her family had no specific history. She had smoked 40 packets a year and had no history of exposure to asbestos. The chest roentgenogram revealed a nodular shadow within the upper lobe of the right lung. A subsequent chest CT showed a $10-\mathrm{mm}$, well-circumscribed, intrapulmonary nodular lesion in the anterior segment of the right upper lobe of the lung. There was no mediastinohilar lymphadenopathy. CT scans also showed that the nodular lesion had progressively increased in size from $10-\mathrm{mm}$ to $18-\mathrm{mm}$ in 6 years. In June 2007, positron emission tomography (PET) using 18-F fluorodeoxyglucose (FDG) showed negative FDG uptake in the lesion (Fig 1). The physical findings were all within normal limits. No abnormalities were found in blood tests. Thus, following the diagnostic confirmation of a pulmonary nodule, surgery was performed in the right lung, which was removed by a wedge resection of the upper lobe through a right posterolateral thoracotomy in June 2007. No specsific identification could be made of malignant or benign on the intraoperative frozen section examination. Hence a right upper lobectomy was performed for complete excision of the tumour. The postoperative course was uneventful.

In the resected specimen, the tumour dimension was 15 $\mathrm{mm}$ at its greatest diameter and was well circumscribed. The tumour was completely surrounded by the lung tissue, and its distance from the visceral pleura was $2 \mathrm{~cm}$. Histologically, the tumour, which was well separated from the normal lung parenchyma, showed a "paternless pattern" proliferation of spindle cells (Fig. 2A). Immunohistochemically, tumour cells showed an entirely positive reaction to the CD34 (Fig. 2B), while cytokeratin antibodies were negative. With these morphological and immunohistochemical findings, the final diagnosis was solitary fibrous tumour. 
Thirty-four months after surgery, she was found to be healthy without any recurrence.

\section{Discussion}

Solitary fibrous tumours are rare, slow-growing mesenchymal neoplasms thought to originate from submesothelial connective issue (6). As far as intrapulmonary solitary (localized) fibrous tumours are concerned, 12 previous case reports have so far been reported in the literature. The tumours were initially described in the pleura, but they have recently been found to originate in many other sites $(1,4)$. They most commonly arise from the parietal and visceral pleura, grow in a nodular and expanding pattern into the pleural cavity, and are often pedunculated (7).

SFTs are common during the fifth and sixth decades, with no sex predominance (2). No etiologic agent has been identified; in particular there is no link with smoking or asbestos exposure (8). Clinically, these tumours are often found inci-

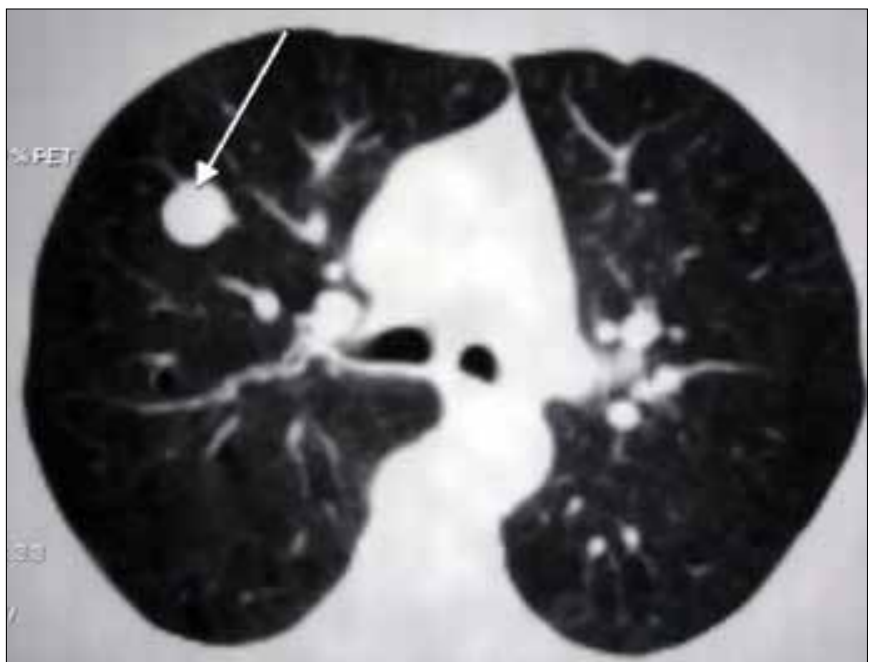

Figure 1. Positron emission tomography (PET) using 18-F fluorodeoxyglucose (FDG) showed negative FDG uptake in the lesion

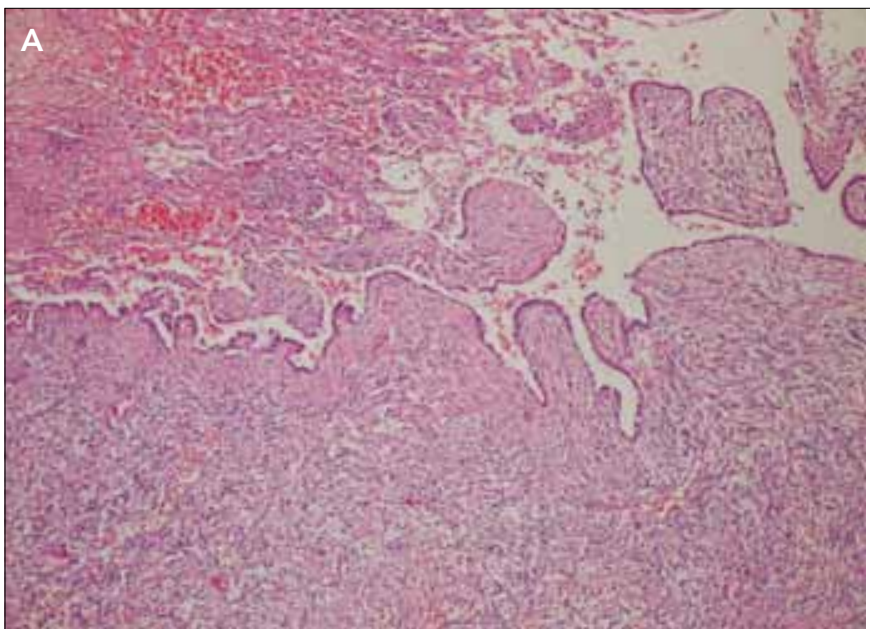

dentally on chest reontgenograms. CT demonstrates welldelineated, noninvasive, noncalcified, and highly enhanced masses (5). They are classified as benign or malignant. Because they lack distinctive histologic features, an immunohistochemical examination is very important for their diagnosis. Immunohistochemically, all the SFTs apppear to demonstrate vimentin and $C D 34$ reactivities, and invariable negativity for keratin (8). In our case CD 34 reactivity was found to be positive and keratin negative.

Classically, solitary fibrous tumours of the pleura are exophytic pedunculated masses that extend from the visceral pleura into the thoracic cavity, and inward growth into the lung parenchyma is extremely rare. When tumours grow into the peripheral lung parenchyma, the term "inverted" has been used to describe such pleural-derived tumours $(2,9)$. In the present case, the tumour did not show morphologic and histologic continuity with the visceral pleura; thus the tumour was considered to have arisen from the parenchyma of the lung.

The clinical behaviour of the tumour is unpredictable (1). Intraparenchymal presentation of SFT has been associated with a higher incidence of aggressive or malignant behaviour (9). The incidence of aggressive behaviour is variously reported as between $13 \%$ and $23 \%$ of cases in most large series of pleural tumours. The highest risk of recurrence was seen in tumours of pathologically malignant and morphologically sessile types. Chemotherapy and radiotherapy are generally considered ineffective for these tumours; however, Saynak et al. reported a patient with recurrence of SFT, which had a significant response to external thoracic radiotherapy (10). To date there has been no report concerning postsurgical recurrence in published intrapulmonary solitary fibrous tumours, inclusive of the present case. It is clear that long-term follow-up of these patients is necessary $(1,4,8)$. In the present case the follow-up period after surgery was 34 months.

In conclusion, a solitary fibrous tumour arising from the lung parenchyma is extremely rare. Complete surgical resection is the best treatment in SFTs, but further follow-up studies are needed to shed light on their clinicopathologic behaviours.

Figure 2. A) Histologically, the tumour which was well separated from the normal lung parenchyma, showed a "paternless pattern" proliferation of spindle cells, B) Immunohistochemically, tumour cells showed an entirely positive reaction to the CD34 


\section{Conflict of Interest}

No conflict of interest was declared by the authors.

\section{References}

1. Goodlad JR, Fletcher CDM. Solitary fibrous tumour arising at unusual sites: analysis of a series. Histopathology 1991;19:515-22. [CrossRef]

2. Sakurai H, Tanaka W, Kaji M, Yamazaki K, Suemasu K. Intrapulmonary localized fibrous tumour of the lung: a very unusual presentation. Ann Thorac Surg 2008;86:1360-2. [CrossRef]

3. Sagawa M, Ueda Y, Matsubara F, Sakuma H, Yoshimitsu Y, Aikawa $\mathrm{H}$, et al. Intrapulmonary solitary fibrous tumour diagnosed by immunohistochemical and genetic approaches: report of a case. Surgery Today 2007;37:423-5. [CrossRef]

4. Magdeleinat $P$, Alifano $M$, Petino $A$, Le Rochais JP, Dulmet $E$, Galateau F, Icard P, Regnard JF. Solitary fibrous tumours of the pleura: clinical characteristics, surgical treatment and outcome. Eur J Cardiothorac Surg 2002;21:1087-93. [CrossRef]
5. de Perrot M, Fischer S, Brundler MA, Sekine Y, Keshavjee S. Solitary fibrous tumours of the pleura. Ann Thorac Surg 2002;74:285-93. [CrossRef]

6. Cardillo G, Facciolo F, Andrea O, Cavazzana AO, Capece G, Gasparri $\mathrm{R}$, Martelli M. Localized (solitary) fibrous tumours of the pleura: an analysis of 55 patients. Ann Thorac Surg 2000;70:1808-12. [CrossRef]

7. Kanamori $Y$, Hashizume K, Sugiyama M, Motoi T, Fukayama M, Ida K, Igarashi T. Intrapulmonary solitary fibrous tumour in an eight-year-old male. Pediatr Pulmonol 2005;40:261-4. [CrossRef]

8. Travis WD, Churg A, Aubry MC, Ordonez NG, et al. Mesenchymal tumours. In: Travis WD, Brambilla E, Muller-Hermelink HK, Harris C, eds. World Health Organization Classification of Tumours. Pathology and Genetics of Tumours of the Lung, Pleura, Thymus and Heart, Lyon 2004;141-4.

9. Aufiero TX, McGary SA, Campbell DB, Phillips PP. Intrapulmonary benign fibrous tumour of the pleura. J. Thorac Cardiovasc Surg 1995; 110:549-51. [CrossRef]

10. Saynak M, Bayir-Angin G, Kocak Z, Oz-Puyan F, Hayar M, et al. Recurrent solitary fibrous tumour of the pleura: significant response to radiotherapy. Med Oncol 2010;27:45-8. [CrossRef] 